\title{
Intraoperative Transesophageal Echocardiography in Nepal
}

\section{Arun Maskey ${ }^{1}$, Deewakar Sharma ${ }^{1}$, Man Bahadur KC ${ }^{1}$, Sujeeb Rajbhan- dari', Jyotindra Sharma², Ramesh Koirala², Sidhartha Pradhan², Bhaga- wan Koirala ${ }^{2}$}

\begin{abstract}
:
Intraoperative transesophageal echocardiography is an important tool for intraoperative evaluation of mitral valve repair. A total of 29 patients who underwent intraoperative transesophageal (TEE) between 25 $5^{\text {th }}$ June, 2001 to 30 ${ }^{\text {th }}$ Dec, 2002.at Shahid Gangalal National Heart Centre, Kathmandu were studied. The age ranged from 14 to 48 years with mean age of 30 years. There were 11 male and 18 female patients. Twenty three patiants had mitral valve repair for Severe mitral regurgitation, which was successful in 15 patients and rest underwent prosthetic valve replacement. Five patients had undergone closed mitral commissurotomy with 4 patients having successful dilatation and 1 patient had annular tear which was converted to open repair with mitral valve ring. One patient had huge aortic aneurysm which was successfully repaired. TEE has been proven to be extremely useful in intraoperative evaluation of mitral valve repair and may help to a timely raintervention, if needed,. This is the first study of intraoperative transesophageal achocardiography in Nepal.
\end{abstract}

Key Words: Intraoperative, transesophageal echocardiography (TEE), Mitral regurgitation (MR).

\section{introduction:}

Intraoperative echocardiography is a valuable adjunct in the evaluation of surgical procedures for various cardiac surgical procedures like primary valvular heart disease, thoracic aortic disease and a variety of other indications such as neoplastic of traumatic cardiac disease. Shahid Gangalal National Heart Centre, Kathmandu is only center in Nepal where intraoperative TEE is a routine procedure for evaluation of valve repair. This is the first study of intraoperative TEE in 29 patients undergoing cardiac surgery at Shahid Gangalal National Heart Centre, Kathmandu, Nepal. 


\section{Patients and Method:}

A Total of 29 patients who underwent intraoperative TEE between $25^{\text {th }}$ June, 2001 to $30^{\text {th }} \mathrm{Dec}, 2002$ at Shahid Gangalal National Heart Centre, Kathmandu were studied. The age ranged from 14 to 48 years with mean age of 30 years. 11 were male and 18 were female. Multiplane SMHZ TEE probe (Aloka SSD 2200,5500) was used for the study,

\section{TEE Procedure:}

TEE probe was introduced with the patient in supine position after endotracheal intubations, general anesthesia and sterile draping. Digital introduction and guidance of the instrument around the endotracheal tube was most often all that was needed for oesophageal intubation with occasional anteflexion of neck to allow passage of the TEE probe without disturbing the position of endotracheal tube.

\section{Cardiac Examination:}

The cardiac images were obtained by transducer position as recommended by ASE/SCA guideline for performing a comprehensive multiplane transesophageal examination².

Grading of mitral regurgitation (MR) based on intraoperative TEE was as following: Grade I, II, III, IV. Failure of repair was defined as MR of > Grade II, Mitral regurgitation was defined as by composite Doppler analysis as $\mathrm{O}=$ Absent: [=mild-narrow and localized regurgitant jet without eccentric trajectory; II=moderateregurgitant jet occupying approximately $25 \%$ to $33 \%$ of left atrium without Wraparound; III=moderate-severe regurgitant jet occupying approximately $50 \%$ of the left atrium wraparound and systolic venous flow reversal absent; IV=severe regurgitant jet occupying $>50 \%$ of the left atrium or with significant left atrial wraparound if eccentric and with systolic pulmonary venous flow reversal presents. Postoperative transthoracic echocardiography was performed in all patients evaluated by Intraoperative TEE. 


\section{Indication for TEE:}

The indications for intraoperative TEE were

1. Evaluation of mitral valve repair: 23

2. Evaluation of Closed mitral commissurotomy : 5

3. Evaluation of aortic aneurysm repair : 1

\section{Results:}

All patients had rheumatic valve for replacement or repair. Among 23 patients attemted for mitral valve repair intraoperative TEE findings were suggestive of good repair (MR < grade II) in 15 patients. In rest of 8 patients MR was II or more and was considered unsuccessful. So a second round run of cardiopulmonary bypass was started and valve replaced with a bileaflet prosthetic valve. Among 5 patients who had undergone closed mitral commissurotomy 4 patients had successful dilatation and 1 patients had annular tear with moderate to severe mitral regurgitation which was timely detected by intraoperative TEE and which was successfully repaired with mitral valve ring. One patient had huge aortic aneurysm which was successfully repaired.

\section{Discussion:}

Mitral valve repair is now clearly favored over prosthetic valve replacement for the surgical treatment of mitral regurgitation, ${ }^{4,5,6,7}$. Mitral valve repair is associated with improved operative ${ }^{6}$ and late mortality ${ }^{7}$ and with minimization at potential complications associated with mitral prosthesis such as thromboembollam ${ }^{7,8}$ infective endocarditis $^{9}$ and bleeding secondary to anticoagulant therapy ${ }^{11}$. Vital to the effectiveness of mitral valve repair is intraoperative assessment of mitral competence after reconstructive procedure. Rheumatic heart disease is the commonest cardiac disease in $\mathrm{Nepal}^{10}$ and rheumatic mitral regurgitation was most common indication for intraoperative TEE in the study. Semiquantitation of mitral regurgitation severity by TEE color doppler imaging in which Jet width at the regurgitant orifice, central Jet area and dimensional ratio are compared with those of the left atrium has been shown to correlate with gradation by left ventricular angiography ${ }^{11}$. In 143 patients studied for mitral valve repair for mitral regurgitation studied by intraoperative TEE by Freeman et al., Mostly with myxomatous disease with or without chordal rupture, significant mitral regurgitation was detected by composite TEE doppler study in 11 (7.7\%) patients and promted successful revision or replacement in 
a11 but 1 patient $^{12}$, In our study successful mitral valve repair was done in 15 out of 23 selected patients with severe mitral regurgitation. Intraoperative TEE evaluation led to the decision of replacement in rest 8 patients. Mitral valve repair is a standard technique with low mortality,complication and reoperation rate. Most mitral valve repair failures appeared to be valve related, progressive primary valvular disease, endocarditis or leaflet retractioni. Mitral valve regurgitation is known complication requiring valve replacement in patients with severe mitral stenosis undergoing closed mitral commissurotomy. In the study 4 patients had successtul opening of mitral valve in severe mitral stenosis, One patient had annular tear with moderate to severe mitral regurgitation detected by intraoperative TEE and timely successful mitral valve repair was performed. One patient had huge aortic aneurysm which was successfully repaired. Intraoperative TEE was useful in delineation of arch. Because the esophagus lies in close proximity of the thoracic aorta, especially the distal arch and the descending portion imaging from the vintage point provides multiple outstanding echocardiography windows for the delineation of aortic anatomy and abnormalities.

\section{Complication:}

No complications related to TEE were noted in the post operative period. There was no incidence of hoarseness of voice, pharyngeal or esopharyngeal trauma.

\section{Limitation of the study:}

This is small study of only 29 patients. Only 23 patients with severe rheumatic matral legurgitation were selected for mitral valve repair.

\section{Summary:}

Intraoperative transoesophageal echocardiography has proven to be extremely useful in evaluation of the quality of mitral valve repair and timely re-intervention if needed. Wider use of Intraoperative TEE should be practiced during cardiac surgical procedure especially during mitral valve repair. 


\section{Reference:}

1. Freeman WK, D'Leary PW, Abel MD, Lossaso TZ, Muzzi DA. Intraoperative application of transesophageal echocardiography. In: Freeman WK, Seward JB, Khanderia BK, Tajik AJ, editots. Transesophageal Echocardiography, $1^{\text {st }}$ edition. Minnesota, 1994:541-48

2. Shanewise J S, Cheung AT, Aronson S, Stewari W J, Weiss L, Mark Bu, Savage $\mathrm{R}$ M, et al. ASE/SCA Guidelines for performing a comprehensive intraoperative multiplane transesphageal Echocardigraphic examination. Recommendation of the American Society of Echocardigraphy council for intraopergtive Echocardigraphy and the Society of cardiovascular anaesthesiologists task force for certification in perioperative transoesophageal Echocardigraphy. Cardovascular anaesthesia.1999- 89: 870-64.

3. Taams M A, Gussenhoven WJ, Schippers LA et al. The value of transesophageal, echocardiography in assessment of aortic dissection, Circulation 1991; 84: 1903-14

4. Carpentier A, Chauvaud S, Fabiani JN et al. Reconstructive surgery of mitral valve incompetence : ten year appraisal. J Thorac Cardiovas Surg.1980;79:338-48

5. Galloway AC, Colvin SB, Baumann FG et al. Current concepts of mitral valve reconstruction for mital insufficiency. Circulation 1988;78:1087-98

6. Cosgrove DM, Chavez AM, Lytle BW et al. Results of mitral valve reconstruction, Circulation 1986,74 suppl 1: 1-82-I-7

7. Orszulak TA, Schaff HV, Danielson GD et al . Mitral regurgition due to ruptured chordae tendene: early and late results of valve repair. J Thorac Cardiovasc Surg 1985; 98: 491-8

8. Galloway AC, Colvin SB, Bauman FG et al, Long term results of mitral valve reconstruction with carpentier tachinique in 148 patients with mitral insufficiency. Circulation 1988; 78 suppl 1: 1-97-1 
- NEPALESE HEART JOURNAL

9. Sand ME, Naftel DC, Blackstone EH et al. A comparison of repair and replacement for mitral valve incompetene. J Thorac Cardiovasc Surg 1987;94:208-19

10. Limbu YA, Maskey A. Current status of rheumatic fever and rheumatic heart disease in Nepal, Annual Report. Shahid Gangalal National Heart Centre.2001/2002,41-45.

11. Kamp O, Dijkstra J-W , Hultink H et al. Tranesophangel color flow mapping in the assessment of native mitral valvular regurgitation: comparision with left ventriculography, J Am Soc Echocardiogr 1991:4: 598-606.

12. Mavioglu 1, Dogan DV, Ozeren M, Dolgun A, Yucel E. Valve repair for rheumatic mitral disease, J heart Valve Dis. 2001; 10:596-602.

For correspondence; Dr, Arun Maskey

Shahid Gangalal National Heart Centre, Bansbari, Kathmandu, Nepal. Fax: (977 1) 371123.e-mail:maskey @ yahoo.com.

1. Department of cardiolagy, Shahid Gangalal National Heart Centre, Kathmandu.

2. Department of cardiovascular surgery, Shahid Gangalal National Heart Centre, Kathmandu. 